\title{
INTERVENÇÃO MEDIACIONAL E PROMOÇÃO DA SAÚDE COM CRIANÇAS PRÉ-ESCOLARES
}

\section{MEDIATIONAL INTERVENTION AND PROMOTION OF HEALTH WITH PRE-SCHOOL CHILDREN}

\section{INTERVENCIÓN MEDIACIONAL Y PROMOCIÓN DE LA SALUD COM NIÑOS PRE-ESCOLARES}

\author{
Kéllen Campos Castro Moreira ${ }^{1}$
}

\begin{abstract}
RESUMO
O Programa MISC (Mediated Intervention for Sensitizing Caregivers), a Teoria da Modificabilidade Cognitiva Estrutural (MCE) e a Experiência da Aprendizagem Mediada (EAM) são abordagens capazes de promover o desenvolvimento e o ensino-aprendizagem através do uso de critérios de mediação. Os cinco critérios mediacionais foram aplicados em oficinas de educação em saúde com crianças pré-escolares. Objetiva relatar a mediação na educação em saúde com crianças pré-escolares. Foram realizadas oficinas educativas em uma escola filantrópica, com crianças de três e quatro anos, sobre temas de saúde a partir da perspectiva da intervenção mediacional. Os dados obtidos se deram através da análise das gravações em vídeo e dos desenhos realizados pelas crianças durante as oficinas. Conclui-se a pertinência da intervenção mediacional para a Promoção da Saúde e apropriação pelas crianças dos conceitos de saúde trabalhados durante as intervenções. Contudo, devido ao tamanho reduzido da amostra, novos estudos deveriam ser empreendidos.
\end{abstract}

Descritores: Educação em Saúde; Aprendizagem; Pré-Escolar; Competência Cultural.

\begin{abstract}
The Mediated Intervention for Sensitizing Caregivers (MISC), the Cognitive Modifiability Theory (MCE) and the Mediated Learning Experience (MCA) are approaches that can promote development and teaching-learning through the use of mediation criteria. The five mediational criteria were applied in health education workshops with pre-school children. It objective to show the mediational of health education with preschool children. Educational workshops were held in a philanthropic school, with children of three and four years, on health topics from the perspective of mediational intervention. The data were obtained through the analysis of the video recordings and the drawings made by the children during the workshops. The pertinence of the mediational intervention for the Health Promotion and the appropriation by the children of the health concepts worked during the interventions is concluded. However, due to the
\end{abstract} reduced size of the sample, further studies should be undertaken.

Descriptores: Health Education; Learning; Child, Preschool; Cultural Competency.

\footnotetext{
${ }^{1}$ Enfermeira. Pós-graduação em Docência no Ensino Superior e Saúde Coletiva. Mestrado em Psicologia dos Processos Psicossociais em Saúde e Educação. Enfermeira Especialista de Saúde. Membro pesquisador do Grupo de Estudo e Pesquisa PROmoção em comunicação, educação e LIteracia para a SAúde no Brasil - ProLiSaBr/UFTM.
} 


\section{RESUMEN}

El programa MISC (Mediated Intervention for Sensitizing Caregivers), la Teoría de la Modificación Cognitiva Estructural (MCE) y la Experiencia del Aprendizaje Mediado (EAM) son enfoques capaces de promover el desarrollo y la enseñanza-aprendizaje a través del uso de criterios de mediación. Los cinco criterios de mediación se aplicaron en talleres de educación en salud con niños preescolares. Objetivo relatar la mediación en la educación en salud con niños preescolares. Se realizaron talleres educativos en una escuela filantrópica, con niños de tres y cuatro años, sobre temas de salud desde la perspectiva de la intervención mediacional. Los datos obtenidos se dieron a través del análisis de las grabaciones en vídeo y de los dibujos realizados por los niños durante los talleres. Se concluye la pertinencia de la intervención mediacional para la Promoción de la Salud y apropiación por los niños de los conceptos de salud trabajados durante las intervenciones. Sin embargo, debido al tamaño reducido de la muestra, se deberían emprender nuevos estudios.

Descriptors: Educación em Salud; Aprendizaje; Preescolar; Competencia Cultural.

\section{INTRODUÇÃO}

A educação para a saúde é uma importante estratégia para a adoção de hábitos saudáveis, ou seja para a promoção da saúde. ${ }^{1,2,3,4}$ Apesar do aparato legal e programas direcionados à promoção da saúde $^{1}$, a revisão da literatura pertinente indica a pouca produção científica envolvendo crianças e educação em saúde. E, nas atividades educativas relatadas, geralmente, apresentam como temas a prevenção de doenças, em detrimento de promoção da saúde.

A perspectiva predominante, em atividades educativas, ainda é a doença (patogênica) enquanto deveria ser saúde (salutogênica). ${ }^{2,3,4,5}$ Outro aspecto relevante é o uso de uma linguagem adequada que, com crianças ocorre através do lúdico por despertar a criatividade e aproximar do imaginário e da linguagem infantil. ${ }^{5}$ Metodologias e recursos podem nortear a prática educativa rumo à promoção da saúde infantil. ${ }^{1,2,3,4}$

O Programa MISC (Mediated Intervention for Sensitizing Caregivers) foi elaborado a partir da Modificabilidade Cognitiva Estrutural (MCE) e da Experiência da Aprendizagem Mediada (EAM) que, são abordagens capazes de promover o desenvolvimento e o ensinoaprendizagem através do uso de critérios de mediação. Aponta duas formas de aprendizagem humana: uma refere-se à interação do organismo com o meio ambiente e a outra se trata da EAM, que possibilita o desenvolvimento de ferramentas teórico-metodológicas capazes de produzir Modificabilidade Cognitiva Estrutural (MCE). ${ }^{7,8,9}$

Para que a EAM aconteça, um mediador deve se colocar, intencionalmente, entre o estímulo e o sujeito e utilizar os critérios de mediação. 
Seu uso entre educadores e crianças podem modificar o comportamento cognitivo, social e emocional das crianças e, criar situações de aprendizagem. Faz-se necessário o uso de cinco critérios, denominados de critérios universais de mediação. ${ }^{7,8,9}$

- Focalização (Intencionalidade e Reciprocidade): refere-se a todas as tentativas do mediador (professor, educador, enfermeiro...) para garantir que o mediado (população, indivíduo, aluno...) foque a atenção em algo que ele deseje. Deve estar claro a intenção do mediador e haver a reciprocidade do mediado através de suas respostas verbais e não verbais ao comportamento do primeiro.

- Expansão ou Transcendência: presente quando o mediador tenta expandir a compreensão do mediado sobre o que está ensinando usando a explicação, a comparação, o acréscimo de novas experiências além das necessárias para o momento.

- Afetividade ou Mediação do Significado: observada quando o mediador utiliza o emocional durante a interação, levando a compreensão do significado dos objetos, pessoas, relações e eventos ambientais.

- Recompensa (sentimento de competência): identificada quando há expressão de satisfação, pelo mediador, quanto ao comportamento do mediado e explicação do motivo de estarem satisfeitos, permitindo-lhes sentimentos de autocontrole, de capacidade e de sucesso, além de expandir sua disponibilidade para explorar ativamente o novo.

- Regulação do comportamento: refere-se à ajuda pelo mediador ao mediado no planejar antes de agir, conscientizando-a da adequação do "pensar" antes de agir, de modo que possa planejar os passos do seu comportamento para atingir um objetivo.

Os critérios não têm uma ordem cronológica para serem utilizados, exceto a focalização que deve ser usada no início da mediação (pode ser usada também em outros momentos) já que deve ter a intenção apresentada claramente e, ter a reciprocidade dos mediados.

Em razão da necessidade de promover saúde, da pequena quantidade de ações educativas no conceito positivo com crianças, da acessibilidade e relevância em usar os critérios mediacionais foram 
realizadas oficinas educativas em uma escola filantrópica, com crianças de três e quatro anos, sobre temas de saúde a partir da perspectiva da intervenção mediacional. O objetivo é relatar a mediação na educação em saúde com crianças pré-escolares.

\section{MÉTODO}

Trata-se de um relato de experiência de educação em saúde com crianças realizada por uma enfermeira, em Minas Gerais, no primeiro semestre letivo de 2016. As oficinas promotoras de saúde iniciaram após aprovação do projeto pelo Comitê de Ética e Pesquisa (CEP) da Universidade Federal de Uberlândia (UFU), estando registrado sob o número 50170714.8.0000.5152, e após assinatura do Termo de Consentimento Livre e Esclarecido, pelos responsáveis.

O local de intervenção foi em uma instituição infantil filantrópica que atende crianças de classe social desfavorecida. Os participantes foram escolhidos pela diretora, consistindo de seis crianças, sendo quatro meninas e dois meninos, com idades entre três e quatro anos. Os materiais utilizados foram:

- Histórias infantis;

- Jogos;

- Vídeo gravações das oficinas;

- Registros das crianças durante as oficinas e descrição.

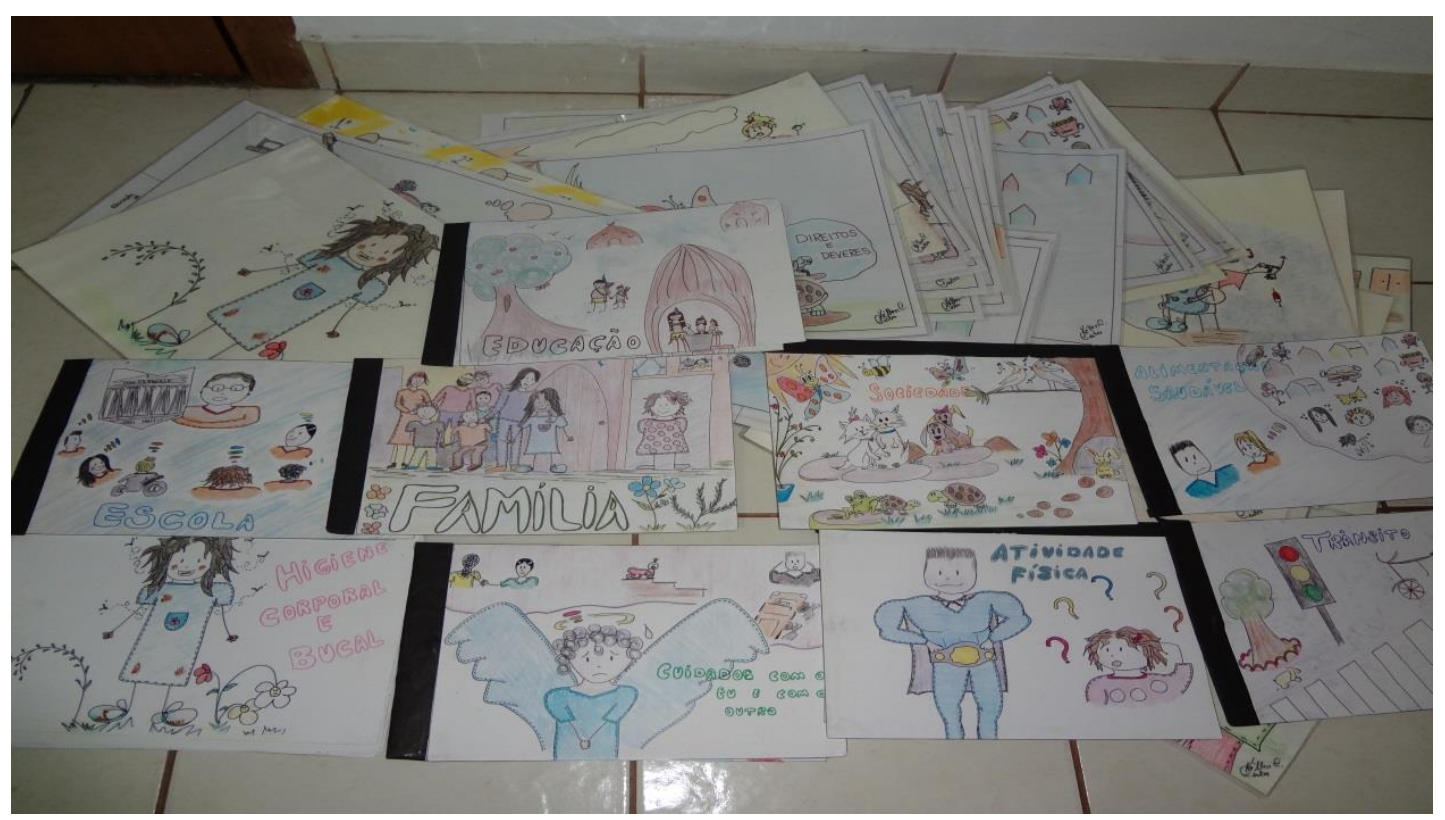

Foto 1: Histórias finalizadas sobre Educação em Saúde 


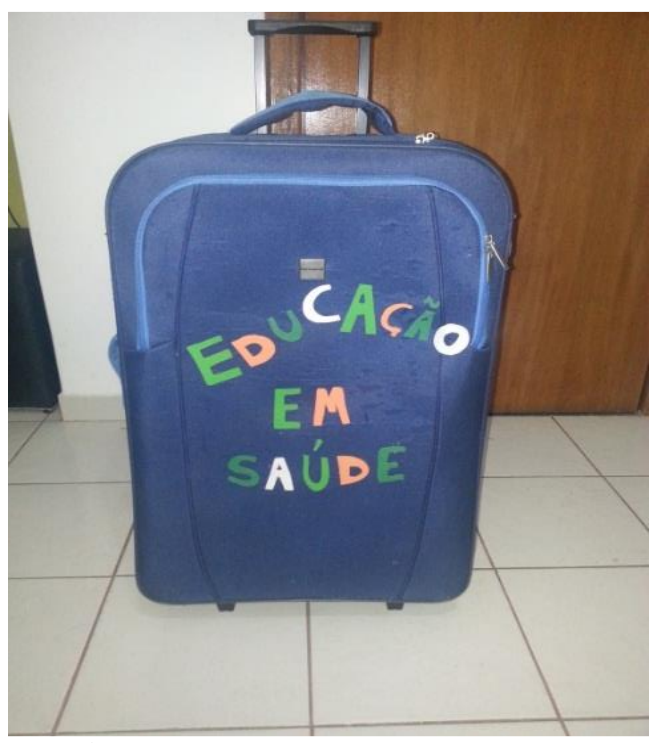

Foto 2: Mala com Jogos

Realizou-se revisão bibliográfica e leituras para elaborar os recursos lúdicos na área de promoção da saúde: nove histórias (temas: atividade física, alimentação, higiene corporal e bucal, escola, sociedade, educação, trânsito, família e, cuidado com o eu e com o outro) e jogos para facilitar a aproximação com as crianças durante as oficinas.

A coleta dos dados ocorreu através das gravações em vídeo das oficinas e dos registros (garatujas) das crianças ao final de cada oficina. Para análise dos dados, após cada oficina ocorreu a transcrição das vídeo-gravações, pela pesquisadora, conforme os critérios de mediação utilizados. Também utilizou-se das garatujas das crianças e seus relatos sobre o que haviam desenhado.

\section{RESULTADOS}

Acredita-se que a mudança nas falas e nas ações, se deva ao uso dos critérios mediacionais e do lúdico. Apesar de não haver relato na literatura e produções científicas do uso dos critérios de mediação aplicados à educação em saúde, os dados provenientes das oficinas demonstraram a pertinência do uso dos critérios de mediação em oficinas de Promoção da Saúde.

A oficina 1 foi realizada com três crianças de 3 anos (criança 1, 2 e 3), com duração de 30 minutos e o tema foi Família; apenas a criança 2 era do sexo masculino. A oficina 2 foi realizada com três crianças de 4 anos (criança 4, 5 e 6), com duração de 47 minutos, tema Família, e com duas crianças do sexo feminino: 4 e 6 . O objetivo destas duas primeiras oficinas foi introduzir a noção de família e suas várias composições 
e, utilizou como recursos folha sulfite, giz de cera, lápis de cor, o livro de história infantil com o tema Família e um quebracabeça do tema Família, os dois últimos produzidos pela pesquisadora.

A oficina 3 foi realizada com três crianças de 4 anos (criança 4, 5 e 6), com duração de 38 minutos e o tema Higiene Corporal e Bucal. A oficina 4 foi realizada com três crianças de 3 anos (criança 1, 2 e 3), com duração de 27 minutos e tema Higiene Corporal e Bucal. Os objetivos das oficinas 3 e 4 foram as crianças aprender os passos da lavagem das mãos e hábitos de higiene e valorizar a higiene diária. Os recursos usados foram história da temática, tinta guache azul, fonte de água (lavatório do banheiro), espelho, toalha de mão, sabonete, folha sulfite, lápis de cor e giz de cera.

Para iniciar as oficinas, a pesquisadora cumprimentou as crianças, já sentadas com elas no tapete e em círculo, em seguida perguntou a elas como foi o final de semana. A partir das falas das crianças, que se referiram à passeios e familiares que conviveram, a pesquisadora fez uso do critério da focalização através da comunicação verbal e não verbal.

\section{Dos $481 \quad$ comportamentos}

mediacionais identificados nas quatro oficinas, $320(66,53 \%)$ referiu-se a Focalização, sendo este o critério de mediação mais usado, seguido de
Recompensa com 12,89\% das ocorrências. A Focalização é o primeiro critério necessário para uma mediação de qualidade. Nas oficinas, independente da idade dos infantes e do tema, esteve muito presente a intencionalidade da pesquisadora e a reciprocidade das crianças manifestada de forma verbal ou não verbal. E, as oficinas que apresentaram maior número de Focalização foram as Oficinas com tema Família. As crianças falaram bastante sobre seus familiares, assim como de episódios cotidianos.

Em seguida, tem-se a Recompensa, que pode aqui ser percebida como resultante da Focalização. As crianças, ao interessarem e interagirem com o mediador sobre a temática explorada, conseguiam compreender e expressar. Assim, o pesquisador utilizou de elogios e encorajamentos, explicando-lhes o motivo de seu comportamento ou raciocínio estar adequado.

A Expansão foi o terceiro critério mais usado, com 43 ocorrências $(8,94 \%)$. Este critério foi de valia para explicitar hábitos de higiene em forma sequencial, assim como de aumentar as variáveis de conceitos conhecidos previamente pelos infantes. Regulação do Comportamento foi o quarto mais utilizado, identificado em $6,03 \%$ das ocorrências.

O critério mediacional menos usado foi Mediação do Significado, presente em 
apenas $5,61 \%$ do total de ocorrências. Infere-se sua pequena frequência pela pouca intimidade do mediado com os participantes ${ }^{9}$, pela necessidade de realizar as atividades propostas e pelo tempo limitado das oficinas.

\section{DISCUSSÃO}

A cada semana a diretora escolheu o tema da oficina, a fim de atender a realidade local. As oficinas seguiram a ordem de contação de história utilizando os critérios de mediação, jogo e desenhos das crianças. As filmagens das oficinas foram analisadas e transcritas, conforme os critérios mediacionais.

Cada oficina foi iniciada com o cumprimento da pesquisadora às crianças já sentadas no tapete e em círculo, seguido da pergunta sobre como estavam, e como foi o final de semana. Tais perguntas serviram para usar o critério de focalização, já que foi apresentado o tema da oficina (deixando claro a intenção do pesquisador) e correlacionando ao cotidiano das crianças (obtendo reciprocidade), segue um exemplo: Ah, que legal (criança 1) você visitou seu primo!!? - direcionando o olhar e as mãos para a criança 1. Então, e hoje vocês estão falando de primo, de mamãe, de irmão... Vocês passaram o final de semana com a família de vocês!? E, hoje eu trouxe uma historinha aqui da família. Todo mundo tem uma família. Quem que é a sua família? - se direcionou para a criança 2. Sendo este o critério inicial da mediação, e que deve ser obrigatoriamente utilizado. ${ }^{7,8,9}$ Conforme a história com o tema Família foi contada, as crianças complementaram com falas e concluíram quem era sua família. A explicação, comparação e acréscimo de experiência por parte da pesquisadora consistiu no uso do critério de expansão: Para esse menininho aqui, o Samuca, ele fala que família é quem mora com a gente. Família é só quem mora com gente? a criança 2 respondeu É- acenou também afirmativo com a cabeça. A pesquisadora continuou a história e: A Alê (demonstrando na imagem do livro a personagem) acha que família é quem cuida, quem ajuda, com quem a gente come todos os dias em casa juntos, quem leva para a escola... E, a Sugismunda fala que aprendeu na escola que é quem cuida. Quem que cuida de vocês? A criança 2 arregalou os olhos e respondeu: O meu pai cuida, a Érica cuida de mim e o meu e a mamãe cuida de mim!. É este critério de mediação que permite ampliar o conhecimento e auxiliar no desenvolvimento. Em conjunto com o critério seguinte permite que o mediado avance da Zona de Desenvolvimento Real (ZDR) e para a Zona de Desenvolvimento Proximal (ZDP). ${ }^{7,9}$

Como exemplo da mediação do significado tem-se É!? E, aí nessa hora o quê que você come, o quê que você gosta de comer quando está no almoço ou na janta com sua família?. E, 
exemplo do uso do critério da recompensa (sentimento de competência): Ah, aí você ajuda a mamãe!? É isso mesmo, a gente tem que ajudar a família!.

Já a regulação do comportamento ocorreu, por exemplo enquanto a pesquisadora contava a história e a criança 6 crianças viu o coração na história e falou que tinha um e a criança 5 complementou falando que tinha um robô brilhante. Foi preciso que a pesquisadora usasse desse critério: É!? Mas, sobre o quê estamos conversando hoje!? Ah, sobre família, então vamos continuar a historinha!? e, quando a criança 2 comentou sobre seu chinelo e manteve a atenção no chinelo: Que legal, mas veja a gente hoje está falando de família e a sua mãe comprou um chinelinho novo... Estava cuidando de você, igual família!

Das seis crianças participantes, em cinco $(83,33 \%)$, houve alteração de conceitos sobre quem é sua família, atitudes ou atividades que fazem com a família. Inicialmente, mencionaram apenas a mãe, com o decorrer da oficina consideraram pai, irmãos e avós, já que segundo os participantes havia cooperação e participação no cuidado também por estes entes. E, sobre a lavagem das mãos (passos e momento), das seis crianças participantes, as seis $(100 \%)$ demonstraram aprendizagem, e destas, apenas uma $(16,67 \%)$ não conseguiu realizar o passo a passo da higienização das mãos durante o jogo.
Os desenhos realizados pelas crianças, associados à sua explicação (por serem garatujas) foram úteis quanto ao fornecimento de dados da pesquisa. Percebeu-se pelas falas das três crianças de três anos $(50 \%)$, que houve dificuldade na compreensão ou expressão quanto ao quê foi solicitado, já que os desenhos não se referiram a atividades como "cozinhando miojo" (criança de quatro anos), mas sim a "bola, barco e mãe". As crianças adquirem linguagem oral com dois anos, mas, a linguagem e compreensão se relacionam a ação. ${ }^{10}$ Por isso, quando solicitado pela pesquisadora desenhar sobre o que gostavam de fazer em família, não conseguiram elaborar uma situação, mas apenas o concreto (bola, barco, mãe, peixe, pinguim, por exemplo).

Apesar de esta pesquisa ser inédita, já que não há produções científicas utilizando os critérios de mediação à educação em saúde, os dados provenientes das oficinas demonstraram a pertinência do uso dos critérios de mediação em oficinas de Promoção da Saúde. A intervenção mediacional é um recurso tecnológico que apresenta baixo custo, amplo acesso, flexibilidade quanto ao local, faixa etária, situações socioeconômicas e culturais e resultados comprováveis. 
A compreensão das variáveis que se relacionam com hábitos saudáveis de crianças pequenas envolve diversos fatores, desde aspectos familiares até mecanismos subjetivos. Estes hábitos podem ser consequência às oficinas de educação em saúde com uso dos critérios de mediação. Contudo, novos estudos deveriam ser empreendidos já que não há outras pesquisas utilizando os critérios de mediação na promoção da saúde e, ao tamanho reduzido e limitado da amostra. Sugerem-se pesquisas com maior número e diversidade de participantes, e na qual o mediador pertença ao meio social dos mediados. Espera-se que a intervenção mediacional, como um recurso tecnológico de saúde, estimule futuras aplicações em atividades de Promoção da Saúde.

\section{REFERÊNCIA}

1. Ministério da Saúde (Brasil), Secretaria de Atenção à Saúde, Departamento de Ações Programáticas e Estratégicas. Política Nacional de Atenção Integral à Saúde da Criança: orientações para implementação. Brasília, DF: Ministério da Saúde; 2018. 180 p.

2. Pfuetzenreiter MR, Vassoler T, Silva L, Dallazem AP, Weck BC. Educação em saúde para crianças na sala de aula, em Lages, SC. Cid ação. 2014; 8(1):1-13.

3. Gomes AM. Refletindo sobre as práticas de educação em saúde com crianças e adolescentes no espaço escolar: um relato de extensão. Rev Conexão UEPG [Internet]. 2015 [citado em 30 ago 2018]; 11(3): 332-41. Disponível em: https:

//www.revistas2.uepg.br/index.php/conexa o/article/view/7592

4. Figueira AB, Amestoy SC, Cecagno D, Tristão FS, Trindade LL, Correal VA. Visão do enfermeiro frente à prática da educação em saúde no ambiente hospitalar. Cogitare Enferm. [Internet]. 2013 [citado em 30 ago 2018]; 18(2): 31016. Disponível em:

https://revistas.ufpr.br/cogitare/article/view /32580/20695

5. Medeiros EAG, Boehs AE, Heidemann ITSB. O papel do enfermeiro e as recomendações para a promoção da saúde da criança nas publicações da enfermagem brasileira. REME Rev Min Enferm. 2013; 17(2):468-73.

6. Nazima TJ, Codo CRB, Paes IADC, Bassinell GAH. Orientação em saúde por meio do teatro: relato de experiência. Rev Gaúch Enferm. 2008; 29(1):147-51.

7. Feuerstein R, Rand Y, Hoffman M, Miller R. Instrumental enrichment. An intervention program for cognitive modifiability. Illinois: Scott, Foresman; 1980.

8. Klein PS. A developmental mediation approach to early intervention; mediational intervention for sensitizing caregivers (MISC). Educ Child Psychol. 2000; 17(3):19-31.

9. Klein PS, Hundeide K. Early intervention: cross-cultural experiences with a mediational approach. Nova Iorque: Garland Pub; 1996.

10. Sandri MA, Meneguetti SL, Gomes E. Perfil comunicativo de crianças entre 1 e 3 anos com desenvolvimento normal de linguagem. Rev CEFAC. 2009; 11 (1):3441.

RECEBIDO: 26/09/18

APROVADO: 07/12/18

PUBLICADO: 07/19 